\title{
Monitoring Candida parapsilosis and Staphylococcus epidermidis Biofilms by a Combination of Scanning Electron Microscopy and Raman Spectroscopy
}

\author{
Kamila Hrubanova $^{1}$ (), Vladislav Krzyzanek ${ }^{1}{ }^{\mathbb{D}}$, Jana Nebesarova ${ }^{2}$, Filip Ruzicka ${ }^{3}$, \\ Zdenek Pilat ${ }^{1}$ (1) and Ota Samek ${ }^{1, *}$ \\ 1 Institute of Scientific Instruments of the Czech Academy of Sciences, CZ-61264 Brno, Czech Republic; \\ hrubanova@isibrno.cz (K.H.); krzyzanek@isibrno.cz (V.K.); pilat@isibrno.cz (Z.P.) \\ 2 Biology Centre of the Czech Academy of Sciences, CZ-37005 Ceske Budejovice, Czech Republic; \\ nebe@paru.cas.cz \\ 3 Department of Microbiology, Faculty of Medicine, Masaryk University and St. Anne's Faculty Hospital, \\ CZ-65691 Brno, Czech Republic; fruzic@fnusa.cz \\ * Correspondence: osamek@isibrno.cz; Tel.: +420-541-514-284
}

Received: 22 September 2018; Accepted: 20 November 2018; Published: 22 November 2018

check for updates

\begin{abstract}
The biofilm-forming microbial species Candida parapsilosis and Staphylococcus epidermidis have been recently linked to serious infections associated with implanted medical devices. We studied microbial biofilms by high resolution scanning electron microscopy (SEM), which allowed us to visualize the biofilm structure, including the distribution of cells inside the extracellular matrix and the areas of surface adhesion. We compared classical SEM (chemically fixed samples) with cryogenic SEM, which employs physical sample preparation based on plunging the sample into various liquid cryogens, as well as high-pressure freezing (HPF). For imaging the biofilm interior, we applied the freeze-fracture technique. In this study, we show that the different means of sample preparation have a fundamental influence on the observed biofilm structure. We complemented the SEM observations with Raman spectroscopic analysis, which allowed us to assess the time-dependent chemical composition changes of the biofilm in vivo. We identified the individual spectral peaks of the biomolecules present in the biofilm and we employed principal component analysis (PCA) to follow the temporal development of the chemical composition.
\end{abstract}

Keywords: Raman spectroscopy; biofilm; sample preparation; scanning electron microscopy; cryo-SEM

\section{Introduction}

Yeast and bacteria are microorganisms that can live as planktonic cells or in an organized formation called biofilm [1]. During their adherence to surfaces or interfaces and their subsequent proliferation, the cells embed themselves into an amorphous extracellular matrix (ECM) [2], which is composed of extracellular polymeric substances (EPS) produced by the cells $[3,4]$. The presence of ECM is often considered an important characteristic of a mature biofilm [5]. Among the main components of EPS is a mixture of polysaccharides, proteins, and extracellular DNA [6,7]. Since these substances are all highly hydrophilic, the biofilm water content can sometimes be as high as $90 \%$ of the total biofilm mass $[1,8]$.

Microbes in natural ecosystems appear to have a pronounced tendency to colonize various surfaces and each other. The interest in such microbial communities-biofilms-has increased over the last three decades, because the biofilms are important in many aspects of health, biotechnology, etc. [9]. 
The presence of biofilms can lead to human health problems, e.g., biofilm on teeth [10], also known as plaque and a factor in tooth decay and parodontosis, as well as the development of biofilm on medical devices such as catheters or implants [11]. On the other hand, biofilms can be useful, as they are already extensively used in wastewater treatment [12,13] and play a role in biofuel production such as methane generation by methanogenesis [14] or in food production [15]. Life in biofilms is favorable for microbes, bringing advantages such as enhanced persistence and resistance to environmental threats such as antimicrobial agents [16], toxic substances, thermal and oxidative stress [2,17]. Although the composition of biofilms varies depending on the system under study, in general the major component of a biofilm is water. Apart from water and the bacterial cells, the biofilm matrix is a complex formed principally by exopolysaccharides [18]. Moreover, other macromolecules such as proteins, DNA and various products from the lysis of bacteria are present in the biofilm matrix [19]. Studies of biofilms suggest that the biofilm matrix architecture is variable and it contains channels that enable water, nutrients and oxygen flow through the biofilm [20]. However, the detailed architecture of the channels inside the ECM, and the processes operating within them have not yet been fully elucidated [16,20]. Therefore, in this study we have combined suitable microscopic and spectroscopic techniques that could be useful for studying the biofilms.

We examined the biofilm with emphasis on the differences in the apparent structure of the ECM, linked to various sample preparation protocols for SEM. The yeast Candida parapsilosis and bacterium Staphylococcus epidermidis have been studied in this project. These species are frequently found among the normal human microbiota [21,22]. However, in a medical context, the ability to form biofilms allows these microbes to colonize the surfaces of implants, consequently causing difficult-to-treat infections, especially in immunocompromised patients [23,24]. The presence of EPS protects the microbial cells from the natural defenses of the human immune system as well as from the effects of antibiotic treatments $[25,26]$ and thus it complicates the therapy $[1,8]$. Understanding the biofilm structure can contribute to the research of biofilm formation and the underlying biochemical mechanisms. This will help to develop a more efficient treatment strategy for biofilm infections $[27,28]$.

Microbial biofilms are usually investigated by various microscopic techniques including confocal laser scanning microscopy (CLSM) and conventional scanning electron microscopy (SEM) [13,29,30], transmission electron microscopy (TEM) [31], Focused Ion Beam (FIB)-SEM [3] and by special SEM techniques, such as cryo-SEM or environmental-SEM [3,32-34]. The main limitation of the light microscopy techniques is the restricted magnification [35]. This can be resolved by the use of SEM, which provides high-magnification images of the individual bacteria and yeast cells and their location and interaction within the ECM, which is important for understanding the morphology and physiology of biofilms [2,36]. However, a conventional SEM, where the sample is observed in high vacuum at room temperature, is limited due to the need for a dry sample [37]. Biofilms are rich in water and the conventional sample preparation for SEM that includes desiccation as a prerequisite for imaging can cause substantial changes in the ECM and the microbial cell ultrastructure, leading to artifacts $[5,34]$. Chemical fixation with aldehydes and osmium tetroxide treatment help to preserve cell morphology and enhance contrast [38,39], while dehydration with ethanol or acetone series is used for the gradual replacement of the water inside the sample. However, this mode of preparation also causes some artifacts, such as cell membrane discontinuities [40], and it has other deleterious effects on morphology. In the case of cryo-fixation, the biofilm is not dehydrated but kept frozen to obtain high-resolution images closer to the native state of the sample [37,39,41]. It has been proven that in cryo-fixed biofilms, the bacterial ultrastructure preservation and the biofilm organization improved significantly [42]. To reduce the damage inherent to these treatments, various innovative cryogenic sample preparation methods have been developed $[41,43,44]$. One of the simplest cryo-fixation techniques is plunging the sample into a liquid cryogen [45]. In general, plunging into liquid nitrogen is not usually sufficient because of the Leidenfrost effect: a thermally insulating film of vaporized nitrogen forming around the sample, preventing fast cooling and allowing water ice crystals to form inside the specimen [46]. However, cryogens like liquid ethane/propane are often used, for example in electron tomography, 
for fixation of very thin layers [42]. Substantially more effective freezing can be achieved by increasing the pressure during exposure to the liquid cryogen. This can be performed by the high-pressure freezing (HPF) technique [47-50].

We coupled the SEM morphological examination of biofilms with chemical characterization by Raman microspectroscopy. Raman microspectroscopy employs a laser beam that is focused with the microscope objective lens in order to excite and collect Raman scattering from a small volume of the sample. Raman spectra from living microorganisms contain multiple spectral peaks corresponding to unique interatomic vibrations in biomolecules, e.g., nucleic acids, proteins, carbohydrates, and lipids [51-54]. It has been shown that Raman microspectroscopy and Raman imaging can be regarded as the methods of choice for many studies of microorganisms, cells and other biological samples [51,55-65]. Detailed databases of Raman spectral features encountered in biological samples had been published before [60]. When characterizing biofilms using Raman microspectroscopy, the common approach is to analyze the biofilm as a whole. The spectra can be acquired point-by-point at selected positions or using line-scan techniques such as Renishaw StreamLine. In such cases, the Raman signal originates from the cells as well as from the ECM. Nevertheless, it may be useful to separate the ECM contribution from the Raman spectra, in order to fully understand the biochemical processes in the cells embedded in the biofilm matrix. It is well known that such cells express phenotypes that differ from those of their planktonic counterparts, i.a. the increased resistance to chemical treatments.

We employed SEM to study the ECM content and distribution in the biofilm, and the way it translates into its Raman spectral characteristics. The SEM images helped us to estimate the relative proportion of the ECM, which is in most cases ranges between $20 \%$ and $50 \%$ of the total biofilm volume. This means that in the Raman spectra, we observe the signal both from the bacterial cells and from the ECM, proportion of which depends on the growth stage of the biofilm. The proportion of the ECM increases with the age of the biofilm.

\section{Materials and Methods}

\subsection{Biofilm Cultivation}

Two biofilm-positive microbial strains that are often involved in serious infections $[27,36,66]$ were selected as model organisms and examined in this study: the well-characterized ica operon-positive, biofilm and slime producing Staphyloccocus epidermidis strain CCM 7221 (Czech Collection of Microorganisms, Brno, Czech Republic) [4] and Candida parapsilosis BC11 from the Collection of the Microbiology Institute, Masaryk University and St. Anne's University Hospital (Brno, Czech Republic) [66]. The strains included in this study were stored at $-70{ }^{\circ} \mathrm{C}$ in cryo-tubes (ITEST plus, Hradec Králové, Czech Republic). Prior to each experiment, the strains were thawed quickly at $37^{\circ} \mathrm{C}$ and cultivated on Mueller-Hinton agar (Oxoid, Basingstoke, UK) at $37^{\circ} \mathrm{C}$ for $24 \mathrm{~h}$. The microbial cultures were re-suspended in a sterile physiological saline solution (PSS) to the optical density 0.5 of the McFarland scale [54].

In our experiments with the yeast biofilm, the wells of 24-well polystyrene tissue culture plates Nunclon (Nunc, Roskilde, Denmark) containing $1 \mathrm{~mL}$ of Yeast Nitrogen Base medium Difco (Becton, Dickinson and Co., Franklin Lakes, NJ, USA) with $4 \%$ glucose (YNBg) and sterile substrate discs were inoculated with $100 \mu \mathrm{L}$ of standardized cell suspension. Bacterial cultures were cultivated in $1 \mathrm{~mL}$ of brain-heart infusion (BHI) medium (Oxoid) with $4 \%$ glucose (BHIg) under the same conditions. We used standard cover slips or sapphire discs with the diameter $1.4 \mathrm{~mm}$ (No. 16706849, Leica Microsystems, Vienna, Austria) and 6 mm (No. 16770158, Leica Microsystems) as a substrate for HPF freezing and a cover slip (No. 1014/1818, Hecht-Assistant, Paris, France) for plunge freezing and conventional protocols for SEM; cover slips are widely used as a cultivation substrate for in vitro biofilm experiments [67-69]. After $24 \mathrm{~h}$ of incubation at $37^{\circ} \mathrm{C}$ the substrate discs were removed from wells and further processed. 


\subsection{Conventional SEM}

All the samples were imaged by several different high vacuum scanning electron microscopes (SEM) at room temperature. Specifications of the SEM devices and information on the imaging parameters are stated along with each procedure below in the text. Figure 1 summarizes all the sample preparation protocols for conventional SEM used in our experiments.

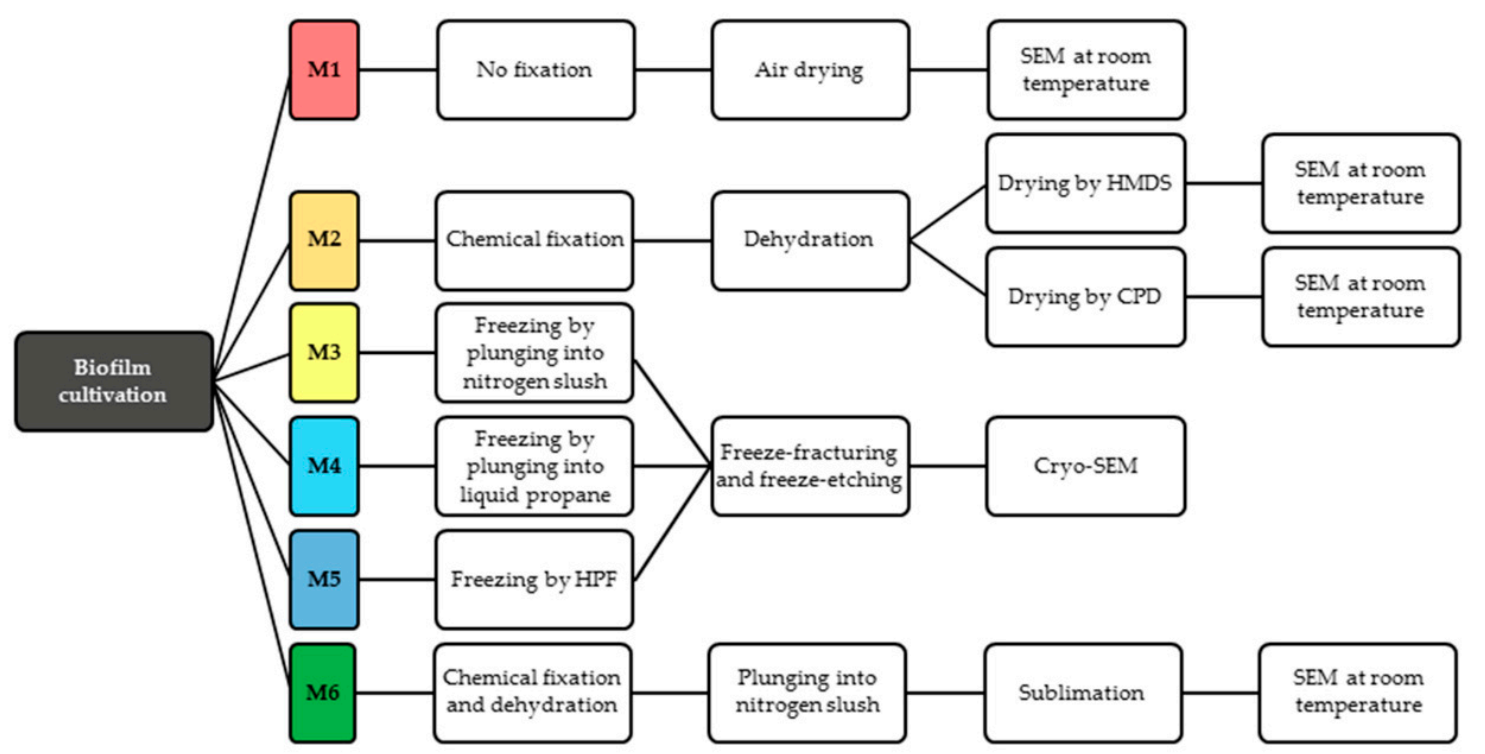

Figure 1. Diagram of microbial biofilm sample preparation for SEM.

\subsubsection{Method 1-Air-Drying (M1)}

The simplest way to visualize the biofilm in vacuum of electron microscope is without any fixation of the structure. The microbial cultures of S. epidermidis and C. parapsilosis were cultivated in a medium for $24 \mathrm{~h}$ on a cover glass. Subsequently, the samples were air dried for $30 \mathrm{~min}$. Imaging of the SE signal was performed by a VEGA TS 5130MM scanning electron microscope (SEM) (Tescan Orsay Holding, Brno, Czech Republic) at the acceleration voltage of $10 \mathrm{kV}$ with the use of a homemade cathode lens with the deceleration voltage in the range around $3 \mathrm{kV}$ and the working distance of $10 \mathrm{~mm}$.

\subsubsection{Method 2-Chemical Preparation (M2)}

The microbial cultures of S. epidermidis and C. parapsilosis after 24-h cultivation under the same conditions as described in previous experiments were prepared according to the standard protocol $[37,70,71]$. Our samples were fixed in $2.5 \%$ glutaraldehyde (Sigma-Aldrich, St. Louis, $\mathrm{MO}, \mathrm{USA})$, post-fixed in $1 \%$ osmium tetroxide $\left(\mathrm{OsO}_{4}\right.$; Sigma-Aldrich) and thoroughly but carefully washed by PBS buffer (Sigma-Aldrich). The process of dehydration by ethanol (VWR Chemicals, Leuven, Belgium) series (30\%, 50\%, 70\%, 80\%, 90\%, 95\%, each step $15 \mathrm{~min}$, and three times 100\%) prepared the samples for drying. Here two methods of drying are compared. The first was done by hexamethyldisilazane (SPI-Chem, West Chester, PA, USA; HMDS; CAS 999-97-3) which was diluted with acetone (Sigma-Aldrich). Therefore, before applying this treatment it was necessary to replace the ethanol with acetone in four steps with increasing proportion of acetone (ratio ethanol/acetone 2:1; 1:1; 1:2; pure acetone) $[37,70,71]$. The second methodology for sample drying is the critical point drying (CPD) using $\mathrm{CO}_{2}$. The samples, prepared by conventional protocols $[37,70]$ were coated by $10 \mathrm{~nm}$ of Au before imaging in a VEGA TS 5130MM SEM at the acceleration voltage $10 \mathrm{kV}$ or in a Magellan 400L SEM (Thermo Fisher Scientific, Hillsboro, OR, USA) at $2 \mathrm{kV}$. 


\subsection{Cryo-SEM}

Our experiments with imaging at low temperature by cryo-SEM show the comparison of the biofilm structure at the same cultivation conditions but with different preparation protocols. We tested multiple cryo-fixation techniques; the workflow is summarized in Figure 1.

\subsubsection{Method 3-Plunging into Nitrogen Slush (M3)}

Freezing in the nitrogen slush was performed in the slushing station, a part of the ALTO 2500 cryo-preparation system (GATAN Inc., Pleasanton, CA, USA) [72,73]. The substrate for the cultivation of the biofilm samples was a cover glass of thickness $0.17 \mathrm{~mm}$ that was removed from the medium without any rinsing immediately before the freezing step. After freezing, the sample was transferred into an ALTO 2500 cryo-preparation chamber, perpendicularly freeze-fractured and subjected to a short sublimation at $-95^{\circ} \mathrm{C}$ for $3 \mathrm{~min}$. The imaging was performed by SEM 7401F (JEOL, Akishima, Japan). The cryo-stage in the SEM was cooled at $-135^{\circ} \mathrm{C}$, the anti-contamination aperture at $-145^{\circ} \mathrm{C}$ during specimen observation. The secondary electron (SE) micrographs were recorded at an electron energy range between 1 and $2 \mathrm{keV}$ (low dose), and the working distance of approximately 6-8 $\mathrm{mm}$ over the fracture plane.

\subsubsection{Method 4-Plunging into Liquid Ethane (M4)}

Freezing in liquid ethane was performed in a homemade plunger. The substrate for cultivation of the biofilm samples was a cover glass of thickness $0.17 \mathrm{~mm}$, which was removed from the medium without any rinsing immediately before the freezing step. After the freezing, the sample was mounted in a standard manner into a cryo-sample holder inside the nitrogen slush, then transferred into an ALTO 2500 cryo-preparation chamber, perpendicularly freeze-fractured and subjected to a short sublimation at $-95^{\circ} \mathrm{C}$ for $3 \mathrm{~min}$. The imaging was performed by SEM 7401F (JEOL, Akishima, Japan) at the same conditions as described above.

\subsubsection{Method 5-Cryo-Preparation by HPF (M5)}

The high pressure freezing was performed by the HPF instrument EM PACT2 (Leica Microsystems) in standard conditions according to the instructions given in the operation manual. With the HPF EM PACT2, it is only possible to freeze sapphire disks with a diameter of $1.4 \mathrm{~mm}$ and therefore they were used as the substrate for the biofilm cultivation. Just as in the case of the plunging fixation the samples were not rinsed before freezing. After freezing, the sample was mounted into a homemade cryo-sample holder in liquid nitrogen [34], then transferred into a cryo-preparation chamber ALTO 2500 , perpendicularly freeze-fractured and subjected to short sublimation at $-95^{\circ} \mathrm{C}$ for $3 \mathrm{~min}$. Imaging was performed by SEM 7401F (JEOL) under the same conditions as described above. Our experiment with high-pressure freezing of the biofilm of Staphylococcus epidermidis was carried out by means of a HPF EM ICE (Leica Microsystems). In this case we used $6 \mathrm{~mm}$ sapphire discs as a cultivation substrate. After the freeze-fracturing in the ACE 600 cryo-preparation chamber (Leica Microsystems) the samples were sublimated for $5 \mathrm{~min}$ at $-95^{\circ} \mathrm{C}$ and then transferred by the VCT 100 shuttle (Leica Microsystems) into a Magellan 400L cryo-SEM (Thermo Fisher Scientific). The fractured structures were observed with a $2 \mathrm{keV}$ electron beam at $-120^{\circ} \mathrm{C}$ and a working distance of around $7 \mathrm{~mm}$.

\subsection{Method 6-Combined Preparation: Chemical and Cryo-Methods (M6)}

Our experiments with combined sample preparation started with biofilm cultivation on the cover glass under the same cultivation conditions as described above, followed by chemical fixation by $2.5 \%$ glutaraldehyde and $1 \% \mathrm{OsO}_{4}$ in PBS buffer and thorough washing with PBS. In the next step, the samples were dehydrated by ethanol series $(30 \%, 50 \%, 70 \%, 80 \%, 90 \%, 95 \%$ v/v ethanol; 15 min each, and three times with $100 \%$ ethanol) and frozen by plunging into the nitrogen slush. After mounting into a standard cryo-sample holder, the samples were transferred into a vacuum 
chamber (ACE 600) where they were sublimated overnight. The samples were then moved under high vacuum using a shuttle (VCT 100) into the SEM (Magellan 400L) and observed with a $2 \mathrm{keV}$ electron beam at room temperature. Working distance was around $6 \mathrm{~mm}$. The samples were metal coated by $2 \mathrm{~nm}$ of Pt.

\subsection{Analysis of the Yeast Biofilm by Raman Spectroscopy}

We used a commercial Renishaw Raman microspectrometer (Renishaw inVia, Renishaw plc., Wotton-under-Edge, UK), with a $785 \mathrm{~nm}$ diode laser as the excitation source. The laser beam was focused on the sample with a microscope lens (Leica, Wetzlar, Germany, 50×, NA 0.5), the laser spot diameter was $2 \mu \mathrm{m} \times 10 \mu \mathrm{m}$ (note that this laser spot shape is characteristic for the Renishaw InVia instrument $[51,64,65])$.

The laser was focused on the surface of the biofilm, which was grown on $\mathrm{CaF}_{2}$ substrate. The samples were measured in two stages: first immediately after the cells were transferred to the substrate (no biofilm), and subsequently after $6 \mathrm{~h}$ of growth at $37^{\circ} \mathrm{C}$, when the fresh biofilm structures were formed. The spectra were measured for $30 \mathrm{~s}$ from different parts of the sample. The power of the excitation laser reached approximately $100 \mathrm{~mW}$ under the objective lens. The Raman spectra were treated with Savitzky-Golay filter to remove noise and with rolling circle filter for background fluorescence removal [74], and subsequently analyzed by principal component analysis [75]. The software was written using MatLab (MathWorks, Natick, MA, USA).

\section{Results and Discussion}

\subsection{Conventional SEM (M1 and M2)}

SEM was found suitable for examination of the microbial biofilms, allowing visualization of microbial cell surfaces and the surrounding ECM with high resolution. Conventional sample preparation protocols for fully hydrated biological material involve following primary steps such as chemical fixation, dehydration and drying. This process modifies the biological material for the low pressure in the SEM chamber during the imaging. The advantages of a microbial biofilm specimen prepared in this manner are its stability, easy manipulation at room temperature, and the possibility of additional coating, which helps to visualize details in the surface structure. Contrarily, the use of chemical treatments and multiple rinsing steps exacerbates the artifacts, especially in the sensitive ECM structure and some parts of the biofilm layer may be completely destroyed.

The presented micrographs (Figure 2) show the comparison of influences of various preparation protocols on the microbial biofilm structure. The easiest way of biofilm preparation for SEM observation is air drying on a cover glass. In the micrographs (Figure 2a,b), the surface structures of the biofilm layer look similar for bacteria and yeast; the air drying caused a collapse of the three-dimensional structure. Moreover, in case of Candida parapsilosis we see that the extracellular space is filled by a dry matrix and the residues of the cultivation medium (Star in Figure 2b). It was not possible to visualize the clear surfaces of microbial cells (Square in Figure 2b) because they were covered by ECM and dry cultivation medium.

The chemical fixation and dehydration by ethanol series allowed preservation of the three-dimensional structure of the biofilm. However, in many areas of the cultivation substrate, the biofilm layer was destroyed and washed away due to the rinsing process during the sample preparation. ECM was partially preserved as a compact and roughened fiber-like matter in the extracellular space (Figure 2c-f, stars). The use of HMDS as a drying solution is a gentler way than $\mathrm{CPD}$, the biofilm layer was less perturbed. Furthermore, the choice of the drying technique following the chemical preparation did not influence ECM quality. Therefore, drying by HMDS is a preferable method of the biofilm preparation for room temperature imaging by SEM whenever cryo-methods cannot be applied. The conventional SEM can be used for observing the surface of bacterial and yeast biofilm and obtaining high-resolution images of the spatial distribution of microbes. It can 
clearly be seen that the sample preparation represents a crucial parameter in the preservation of the three-dimensional structure of the biofilm. The influence of the chemical treatment is most obvious on the spatial architecture of the biofilm and the compact structure of the ECM. The significant disadvantages of the chemical preparation are the partial loss of the biofilm from the cultivation substrate and the time requirements for this process.
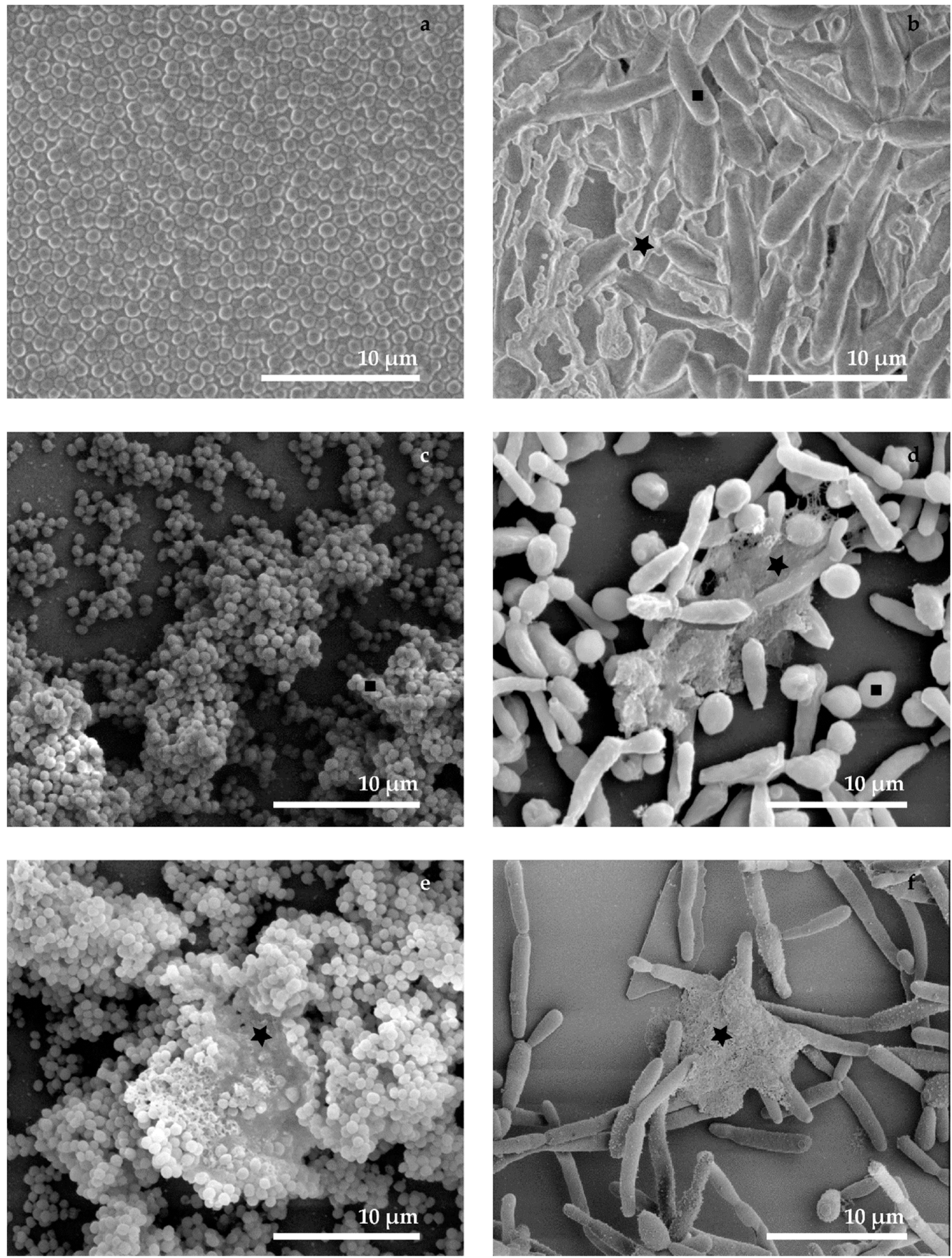

Figure 2. SEM micrographs show the comparison of preparation protocols for microbial biofilm structure (in the left column S. epidermidis and in the right column C. parapsilosis): (a,b) no chemical preparation and air drying; measurement parameters: $10 \mathrm{kV}$ with the use of a homemade cathode lens with the deceleration voltage in the range around $3 \mathrm{kV}$, WD $10 \mathrm{~mm}$; (c,d) chemical sample preparation and drying by CPD; measurement parameters: (a) $10 \mathrm{kV}$ or (b) $2 \mathrm{kV}$, WD $8 \mathrm{~mm}$; (e,f) chemical sample preparation and drying by HMDS. Marks: stars-ECM, squares—cells; measurement parameters: $2 \mathrm{kV}$, WD $8 \mathrm{~mm}$. 


\subsection{Cryo-SEM (M3, M4 and M5)}

The use of low-temperature preparation by cryo-SEM for observing biological samples brings a number of advantages compared to conventional SEM at room temperature. The samples do not have to be fixed by chemicals treatment and rinsed several times by a buffer. Moreover, the dehydration series is eliminated and the lengthy drying is no longer needed, therefore the artifacts associated with these processes are eliminated. On the other hand, the observation of biological structures in SEM at low temperatures requires specialized equipment and has its limitations and drawbacks. It is well known that suboptimal freezing speed during the cryo-fixation causes disruptions to the soft hydrated material due to the water ice crystallization [45]. Therefore, the choice of a particular cryo-fixation technique is crucial to obtain unperturbed structure of the frozen specimen.

The comparison of the freezing methods for yeast and bacterial biofilms is the main aim of this section of our study. The perpendicular freeze-fracture of the samples $(24 \mathrm{~h}$ old biofilms of Staphylococcus epidermidis and Candida parapsilosis) frozen by plunging into nitrogen slush are shown in Figure $3 a, b$.

The inner structure of the microorganisms (Marks-squares in Figure 4) seems to be sufficiently preserved in the range of magnification around $5000 \times$. The thickness of the biofilm layer is approximately $10 \mu \mathrm{m}$. The structure of the ECM containing the extracellular biopolymers and the cultivation medium has a sponge-like character. We consider this structure to represent a micro-segregation $( \pm 0.5 \mu \mathrm{m})$ caused by ice crystal growing during the slow freezing process. The method based on plunging the sample into liquid ethane should be appropriate for freezing a sample with thickness up to $10 \mu \mathrm{m}$ [45]. In our micrographs the final structures after fixation by plunging into liquid ethane look very similar to previous experiments, probably due to the existence of a cultivation substrate such as described in literature [76]. Nevertheless, the use of sapphire discs as a cultivation substrate for plunge-freezing seems to be more suitable from the perspective of their thermal conductivity. However, several experiments show that the plunge freezing fixation of cells cultivated on sapphire discs lead to ice crystal segregation as well [77]; this result also corresponds to our experiments. Noticeably better preservation of the whole microbial biofilm, including the extracellular matrix, is clearly visible in Figure 3e,f (marks-stars). High-pressure freezing ranks among the cutting-edge sample preparation techniques for cryo-SEM. Besides the fast cooling rate, a positive influence is apparently brought by the use of sapphire discs with better thermal conductivity compared to other substrates. The structure of ECM (Figure 3e,f, marks-stars) is very smooth within the magnification used and we were able to detect only minimal disruptions due to the ice crystallization. Moreover, it is possible to recognize the denser parts of the biofilm that can be observed in the surroundings of the microbial cells [34].
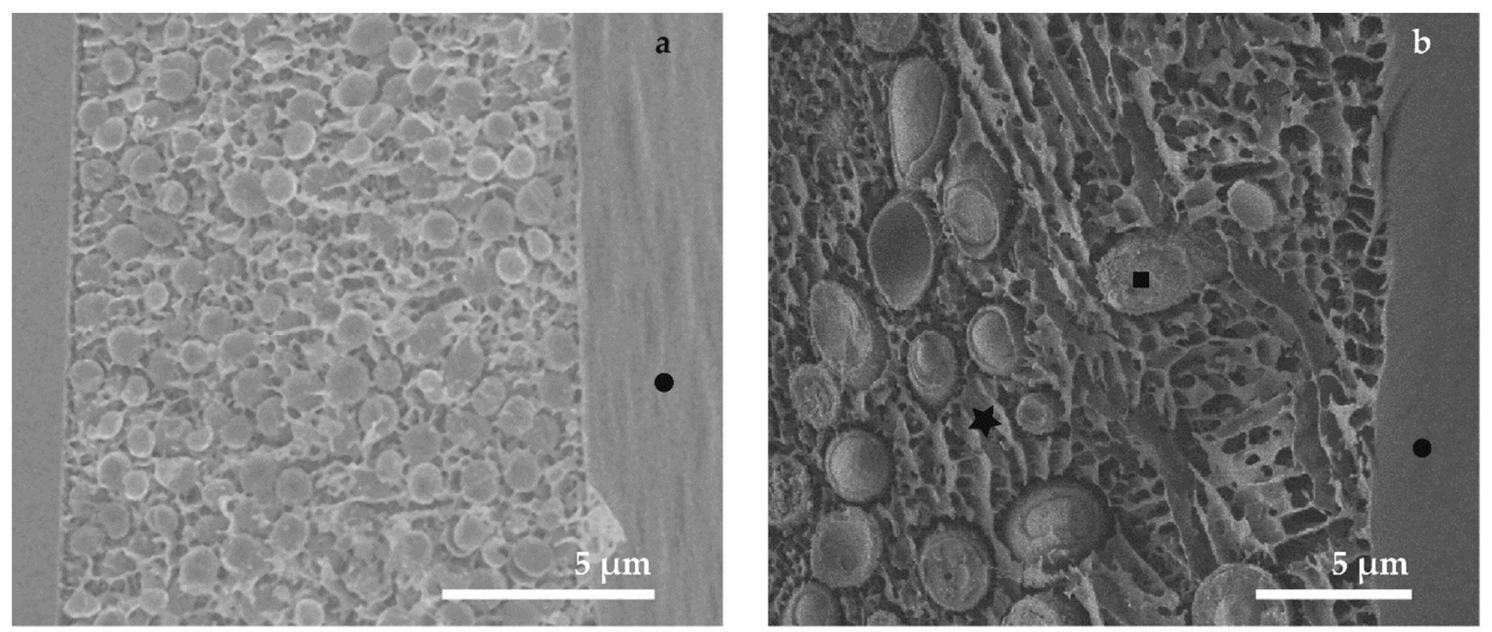

Figure 3. Cont. 

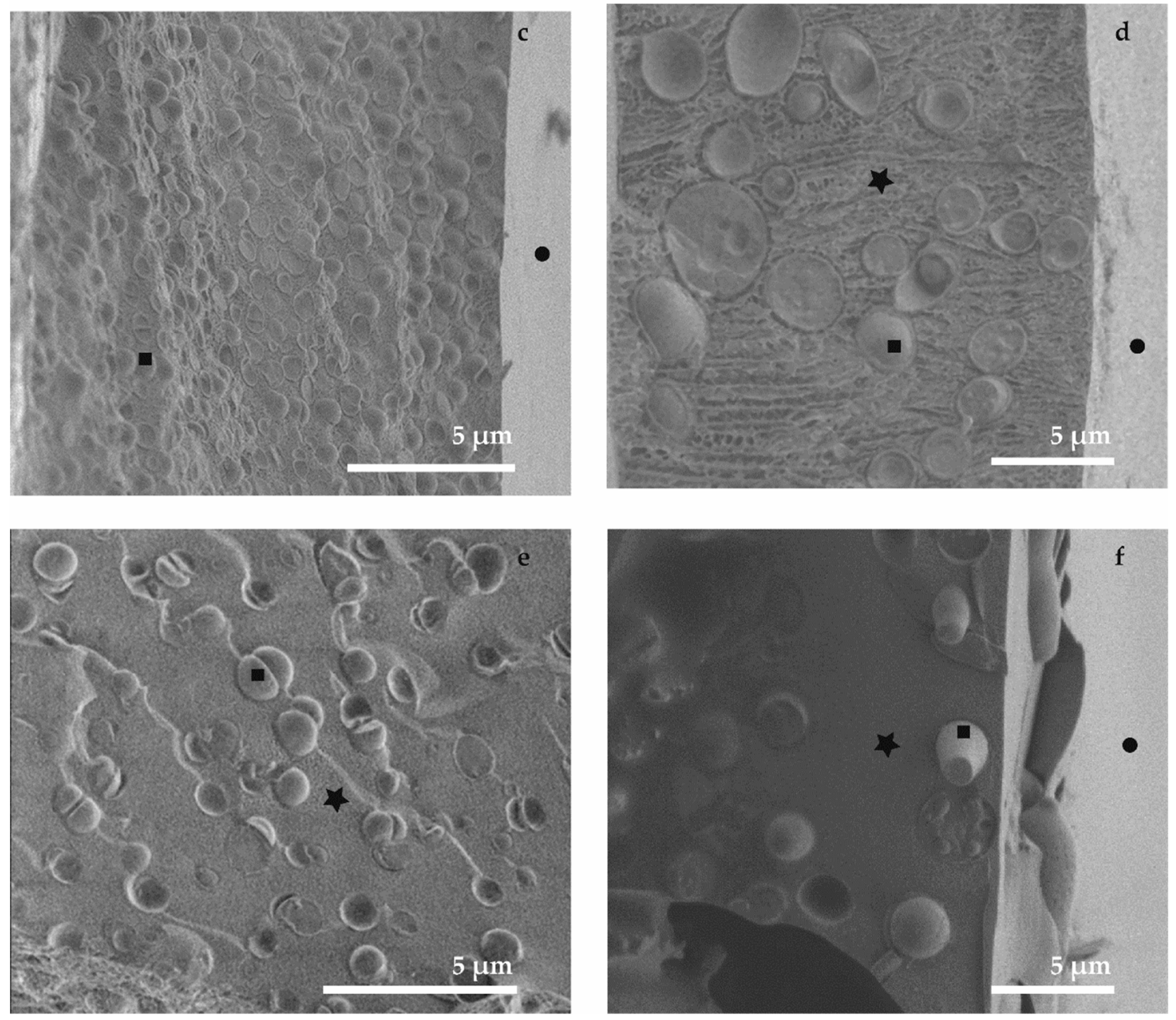

Figure 3. SEM micrographs showing the comparison of preparation protocols applied to microbial biofilms (in the left column S. epidermidis and in the right column C. parapsilosis): (a,b) plunge freezing into nitrogen slush; (c,d) plunge freezing into liquid ethane; (e,f) freezing by HPF. Marks: stars-fully hydrated ECM, squares-microbes, dots-surface of biofilm layer; measurement parameters 1 to $2 \mathrm{keV}$ and $6-8 \mathrm{~mm}$.

Cryo-methods in SEM are capable of providing information about the ultrastructure of the microbial biofilm interior, assuming that freeze-fracturing is applied. It is possible to visualize the areas where microbes adhere to the surface of the cultivation substrate and the contact fields between individual microbial cells. On the other hand, examination of the biofilm surface (Figure 3 , marks-circles) could not be performed, because the biofilm layer was covered by frozen liquid (the cultivation medium with a content of EPS). 

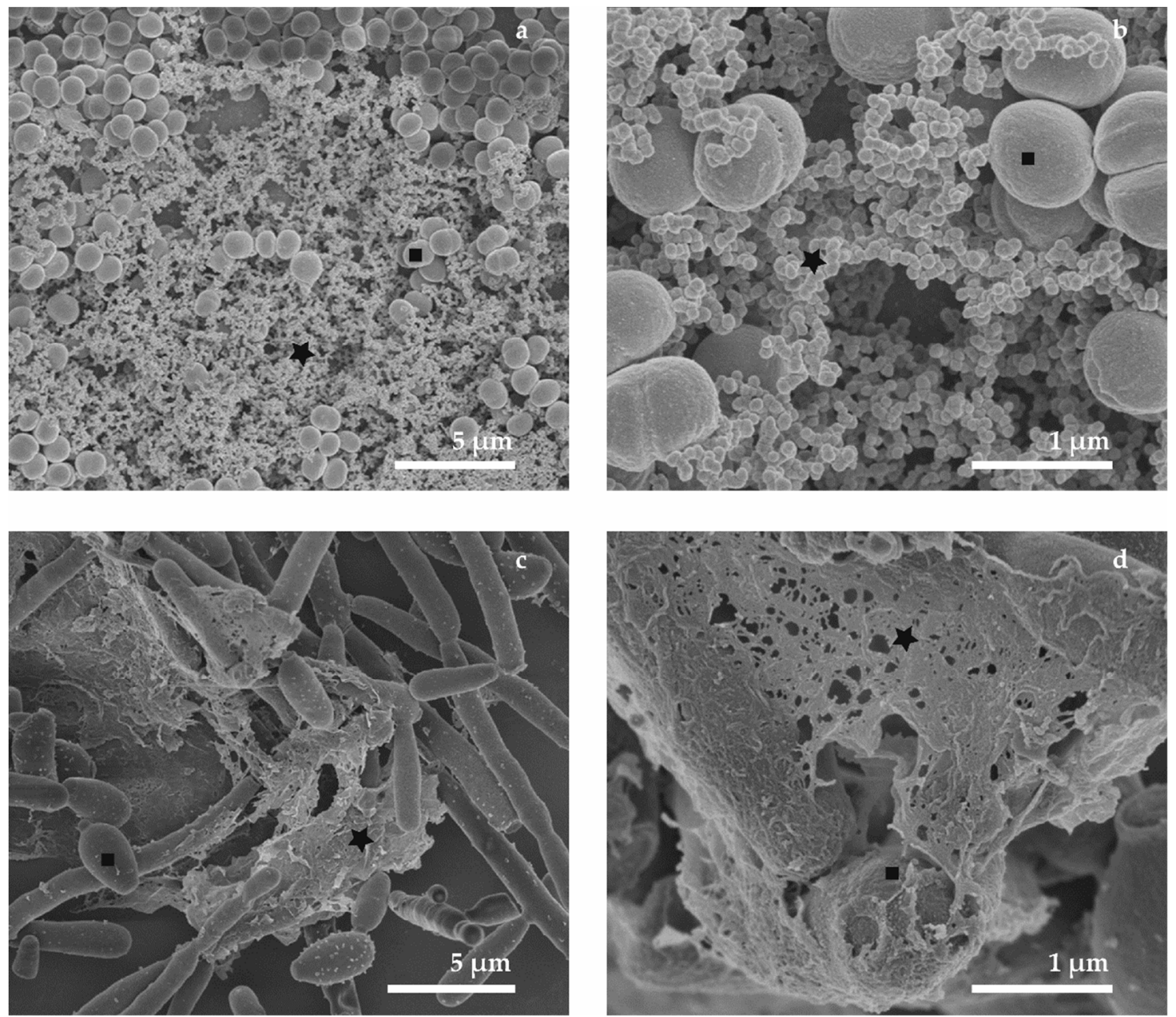

Figure 4. SEM micrographs show the comparison of the bacterial and yeast biofilm structure after the combined sample preparation: (a,b) S. epidermidis; (c,d) C. parapsilosis. In the left column, images are displayed in a lower magnification, while the details are shown in the right column; measurement parameters: $2 \mathrm{keV}$, WD $6 \mathrm{~mm}$.

\subsection{Combined Preparation-Chemical and Cryo-Methods (M6)}

Alternative sample preparation protocol is the combination of chemical fixation by solution of GA and $\mathrm{OsO}_{4}$ and dehydration by the ethanol series such as in the case of biological sample preparation for conventional SEM techniques by the standard chemical method. When the total water content was replaced by $100 \%$ ethanol, the samples in our experiments were frozen by plunging into the nitrogen slush, and transferred to the cryo-preparation chamber where they were sublimated overnight until they were completely dry. The sublimation process started at $-140{ }^{\circ} \mathrm{C}$, then temperature increased to $-80{ }^{\circ} \mathrm{C}$ with a speed of heating $4{ }^{\circ} \mathrm{C} / \mathrm{min}$ for $6 \mathrm{~h}$ and finally samples were left to warm up to the room temperature spontaneously. Additional coating (4 nm, carbon) allowed a production of high-magnification micrographs of our biofilm samples. From our results it can be concluded that the M6 protocol is the most favorable means of biofilm preparation with the aim of surface visualization. The micrographs in Figure 4 show the spatial distribution of microbes and ECM similar to conventional preparation for room-temperature SEM. The ECM (Figure 4, marks-stars) of the bacterial biofilm seems to have an aggregation character which can arise from the chemical treatment during the preparation. The fiber-like structure of the extracellular matrix that covered and interconnected the yeasts bodies looks very similar to the ECM in samples prepared by CPD, but biofilm samples were washed away to a lesser extent due to the absence of chemical drying or CPD. We were not able to detect any evidence of a gel-like matrix covering the microbial cells as described in many 
publications $[1,24,78]$. This is to be expected, because the whole freeze-drying procedure was applied in this method. We found that the visualized structures are the remnants of the cultivation medium and the condensed matrix components. The limitations of the six different preparation techniques for SEM on bacterial and yeast biofilms (M1-M6), the benefits and influence on the biofilm structure are summarized in Table 1.

Table 1. Comparison of benefits and limitations of sample preparation protocols for SEM (Methods M1-M6) and their influence on biofilm structure as shown in schematic drawings. Our best candidates for sample preparation techniques are labelled green.

\begin{tabular}{|c|c|c|c|}
\hline $\mathbf{M}$ & Advantage & Disadvantage & Schema \\
\hline 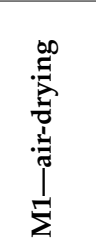 & $\begin{array}{l}\text { Speed of sample preparation } \\
\text { Simplicity } \\
\text { Repeatability of measurement in } \\
\text { SEM at room temperature } \\
\text { Suitable for surface imaging }\end{array}$ & $\begin{array}{l}\text { The loss of the 3D structure } \\
\text { Deformation of microbial } \\
\text { biofilm } \\
\text { Deformation of ECM The } \\
\text { possibility of imaging only the } \\
\text { sample surface (not interior) }\end{array}$ & Deformation of biofilm \\
\hline 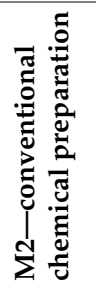 & $\begin{array}{l}\text { Repeatability of measurement in } \\
\text { SEM at room temperature } \\
\text { The 3D structure is preserved. } \\
\text { Suitable for surface imaging }\end{array}$ & $\begin{array}{l}\text { Long-term procedure } \\
\text { Damage of soft biofilm sample } \\
\text { due to multi-steps washing } \\
\text { Artefacts with chemicals } \\
\text { treatment (the change of gel-like } \\
\text { ECM into fiber structures) } \\
\text { The sample surface imaging }\end{array}$ & Biofilm is washed out \\
\hline 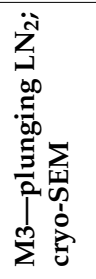 & $\begin{array}{l}\text { Speed of sample preparation } \\
\text { The 3D structure of microbial } \\
\text { cells is preserved } \\
\text { Possibility of biofilm interior } \\
\text { imaging (used freeze-fracturing } \\
\text { technique also suitable for } \\
\text { M3-M5) }\end{array}$ & $\begin{array}{l}\text { Artefacts with freezing } \\
\text { procedure } \\
\text { Freezing is sufficient for very } \\
\text { thin samples } \\
\text { Limitation for surface imaging } \\
\text { because of water content in } \\
\text { biofilm samples }\end{array}$ & I aron \\
\hline 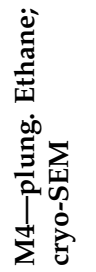 & $\begin{array}{l}\text { Speed of sample preparation } \\
\text { The 3D structure of microbial } \\
\text { cells is preserved } \\
\text { Possibility of biofilm interior } \\
\text { imaging }\end{array}$ & $\begin{array}{l}\text { Artifacts with freezing } \\
\text { procedure (smaller ice crystals } \\
\text { inside biofilm than by M3) } \\
\text { Freezing of thin samples } \\
\text { Limitation in surface imaging } \\
\text { because of water content in } \\
\text { biofilm samples }\end{array}$ & "Small" ice \\
\hline 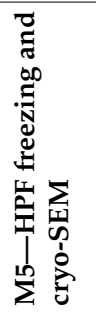 & $\begin{array}{l}\text { Speed of sample preparation } \\
\text { 3D structure of microbial } \\
\text { cells/ECM is nicely preserved } \\
\text { The best freezing technique for } \\
\text { samples with thickness up to } \\
200 \mu \mathrm{m} \text { (exp. tested) } \\
\text { Biofilm interior imaging }\end{array}$ & $\begin{array}{l}\text { Limitation in surface imaging } \\
\text { (water content in biofilm) } \\
\text { Limitations connected with HPF } \\
\text { machine-cultivation substrate } \\
\text { (sapphire discs for freeze } \\
\text { fracturing; Al or Cu-gold discs) }\end{array}$ & $\begin{array}{l}\text { Optimal prep. of biofilm } \\
\text { for interior imaging }\end{array}$ \\
\hline 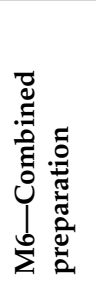 & $\begin{array}{l}\text { Speed of sample preparation } \\
\text { 3D structure of biofilm } \\
\text { Biofilm surface imaging } \\
\text { Repeatability of measurement in } \\
\text { SEM at room temperature after } \\
\text { freeze-drying } \\
\text { Less washed out biofilm }\end{array}$ & $\begin{array}{l}\text { Artifacts from chemical fixation } \\
\text { (the change of gel-like ECM) } \\
\text { The imaging of sample surface }\end{array}$ & $\begin{array}{l}\text { Applicable prep. of } \\
\text { chemically fixed biofilm } \\
\text { for surface imaging }\end{array}$ \\
\hline
\end{tabular}




\subsection{Analysis of the Yeast and Bacterial Biofilms by Raman Spectroscopy}

We assessed the chemical composition of the biofilms using Raman microspectroscopy. Our central objective was to identify the main components of the biofilm. We compared the Raman spectra from the freshly inoculated substrate, containing only the microbial cells, but no ECM, with relatively fresh ( $6 \mathrm{~h}$ old) biofilm, containing a definite proportion of the ECM, see Figure 5 . To this end, we assigned the individual peaks of the measured spectra, see Table 2, and we employed PCA to pinpoint the differences in the chemical composition, see Figure 6. The associated PCA loadings reveal the essential changes associated with the ECM production, see Figure 7. We found the main difference between the freshly inoculated substrate and $6 \mathrm{~h}$ old biofilm is in the production of proteins, sugars, and lipids (peaks 6,7 , and 8 on Figure 5). This stems from the generation of various polysaccharides, proteoglycans, lipopolysaccharides and lipoproteins as the basis of the ECM.
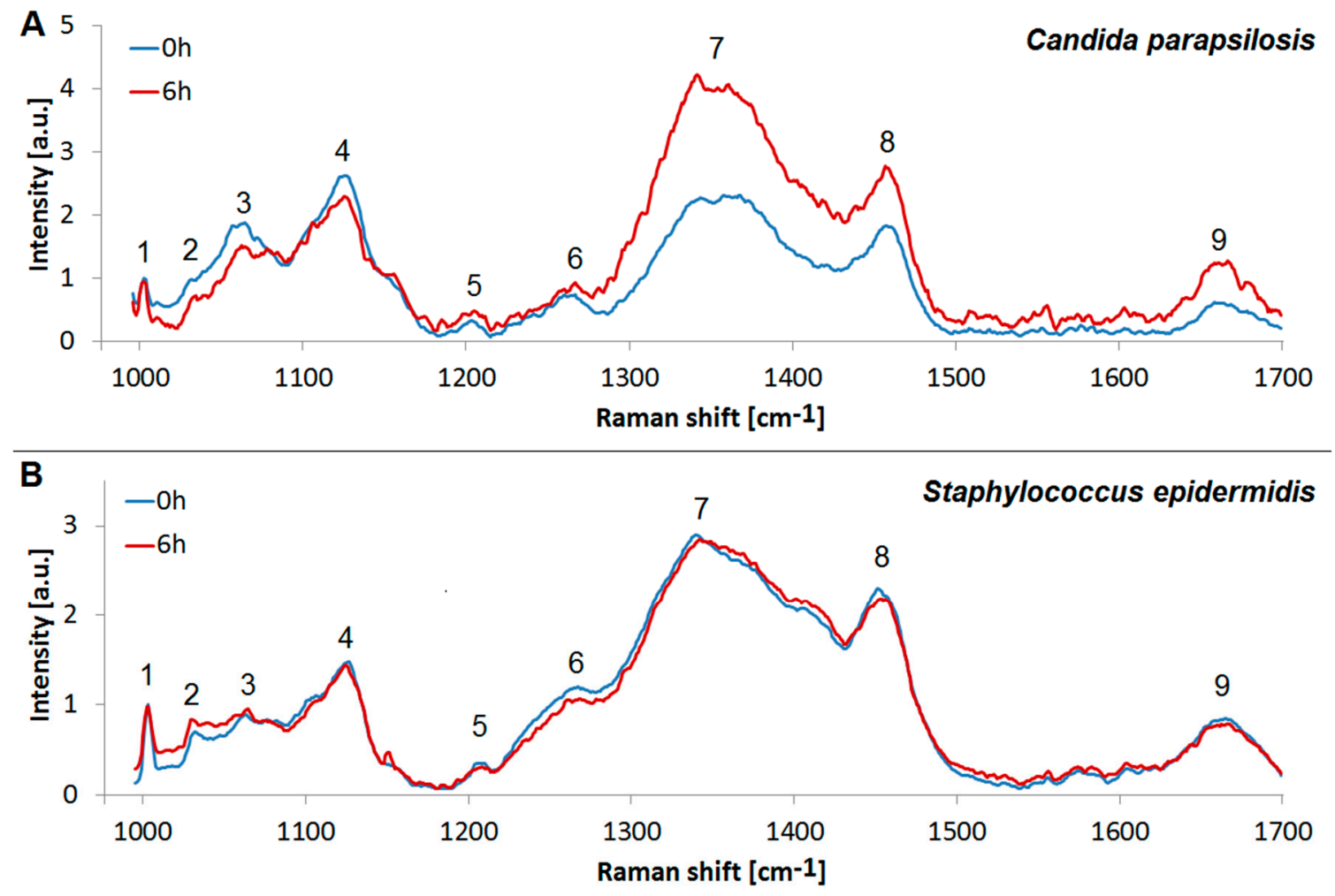

Figure 5. Raman spectra of biofilms. (A): Candida parapsilosis; (B): Staphylococcus epidermidis. Comparison of the freshly inoculated substrates containing no ECM $(0 \mathrm{~h}$, blue $)$ with $6 \mathrm{~h}$ old biofilm, showing the start of the ECM production $(6 \mathrm{~h}$, red). The Raman peaks associated with biomolecules are numbered, see Table 2 for the assignments. The spectra were averaged from six separate measurements.

Table 2. Assignments of Raman peaks of C. parapsilosis and S.epidermidis biofilms [51].

\begin{tabular}{ccc}
\hline No. & Wavenumber $\left[\mathrm{cm}^{\mathbf{- 1}}\right]$ & Peaks Assignment \\
\hline 1 & 1002 & Symmetric-ring breathing of Phe \\
2 & 1033 & C-H in-plane stretch of Phe \\
3 & 1065 & C-C stretch of lipids \\
4 & 1125 & C-N stretch of proteins \\
5 & 1205 & Proteins \\
6 & 1267 & Lipids, Amide III \\
7 & $1340-1360$ & Proteins, Carbohydrates \\
8 & 1456 & CH Scissoring, Lipids $_{2}$ Amide I, Lipids \\
9 & 1660 & Amiss \\
\hline
\end{tabular}




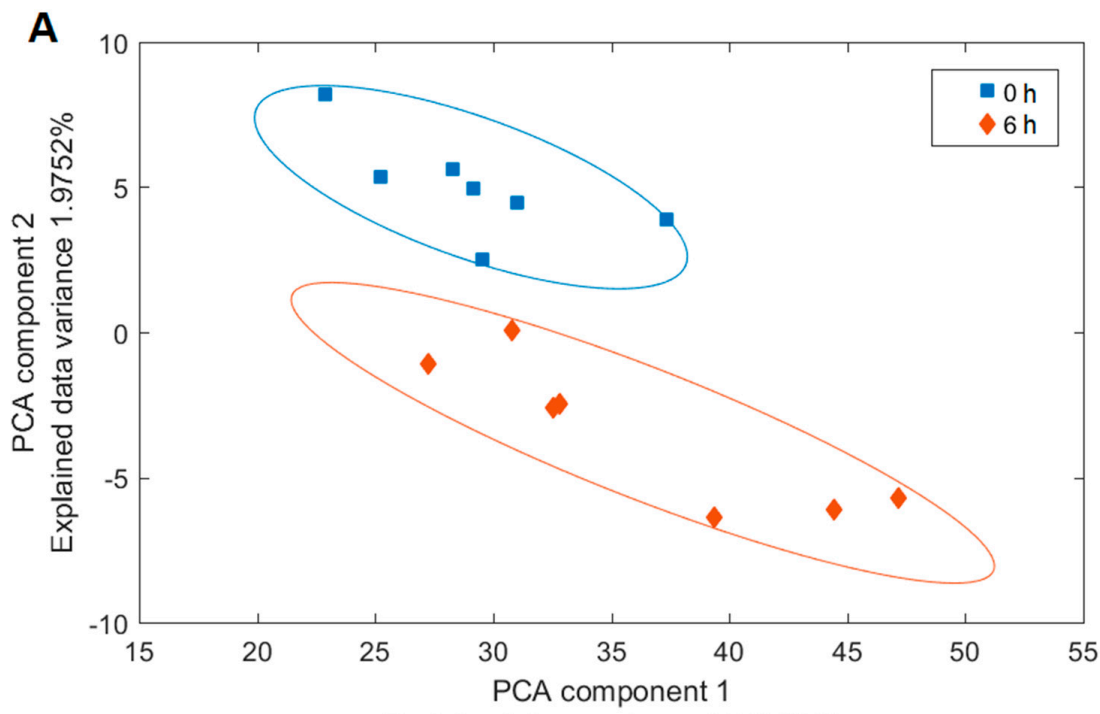

Explained data variance $97.0738 \%$

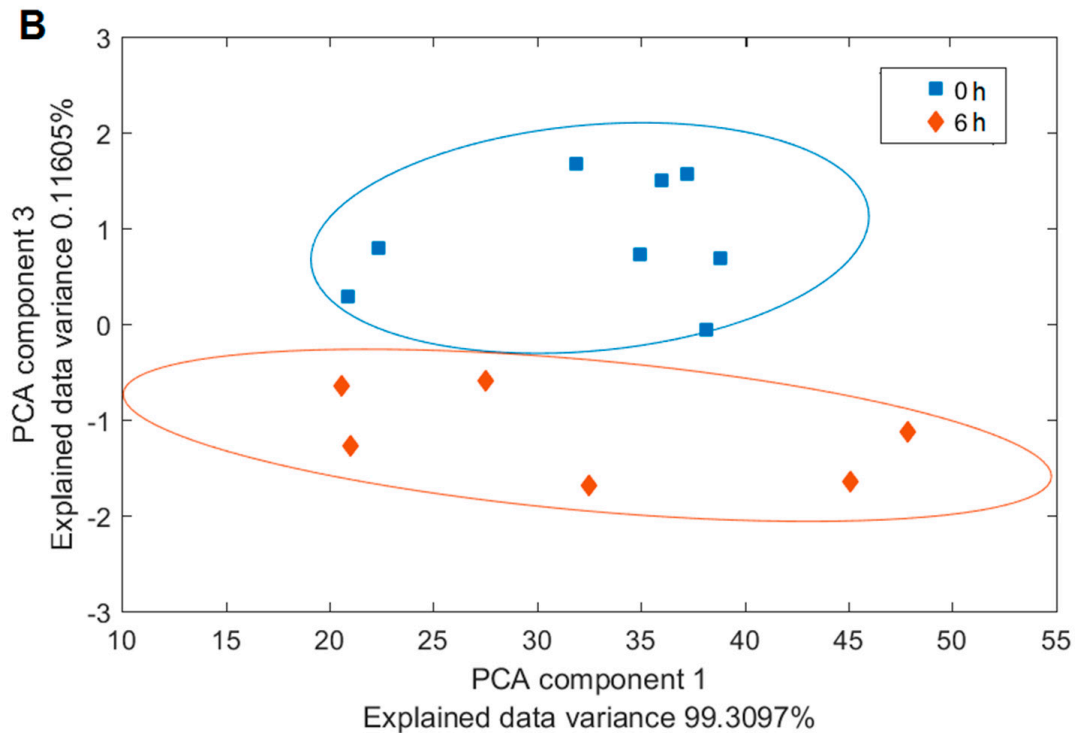

Figure 6. PCA plots for the two species (A) Candida parapsilosis and (B) Staphylococcus epidermidis. The clusters of spectra are associated with the two incubation times. Blue squares $/ 0 \mathrm{~h}$-initial cultures with no ECM; red diamonds $/ 6 \mathrm{~h}-6 \mathrm{~h}$ old cultures with starting ECM formation.

While the differences in the spectra of Candida parapsilosis at $0 \mathrm{~h}$ and $6 \mathrm{~h}$ are very pronounced, especially in the region $1340-1360 \mathrm{~cm}^{-1}$ and $1456 \mathrm{~cm}^{-1}$, Staphylococcus epidermidis spectra at $0 \mathrm{~h}$ and $6 \mathrm{~h}$ show only marginal differences (Figure 5), although they are clearly visible with the aid of the PCA analysis (Figures 6 and 7). This discrepancy is probably caused by the differences in the optimal conditions for biofilm production by the two studied species. Candida parapsilosis, which is eukaryotic, may have developed more complex strategies to react to suboptimal or stressful conditions in general, including the ability to generate biofilm more quickly and efficiently, compared to Staphylococcus epidermidis, in which the biofilm production may be linked only to a specific set of growth conditions. We conclude that while we were able to stimulate the biofilm growth in Candida parapsilosis, in the Raman experiments we did not meet the optimal conditions for biofilm production in Staphylococcus epidermidis. However, it is obvious from the SEM observations, that given enough time, the biofilm growth around the Staphylococcus epidermidis cells is abundant.

The chemical changes associated with the formation of biofilm can be easily observed in the PCA loadings in Figure 7. While the Candida parapsilosis biofilm appears to be composed mainly of 
fungal exopolysaccharides that lack nitrogen in their structure (peaks at $1340-1360 \mathrm{~cm}^{-1}$ ) [60,79], the biofilm of Staphylococcus epidermidis is relatively richer in nitrogen containing polysaccharides such as poly- $N$-acetylglucosamine (peaks around $1400 \mathrm{~cm}^{-1}$ ) $[60,80]$. The ECM of Candida parapsilosis is composed of several groups of chemical components, including presumably the lipoproteins and proteoglycans. In contrast, the ECM of Staphylococcus epidermidis appears to be more chemically uniform. This uniformity apparently stems from the relative simplicity of the bacterial (prokaryotic) metabolism compared to the eukaryotic metabolism of Candida parapsilosis.
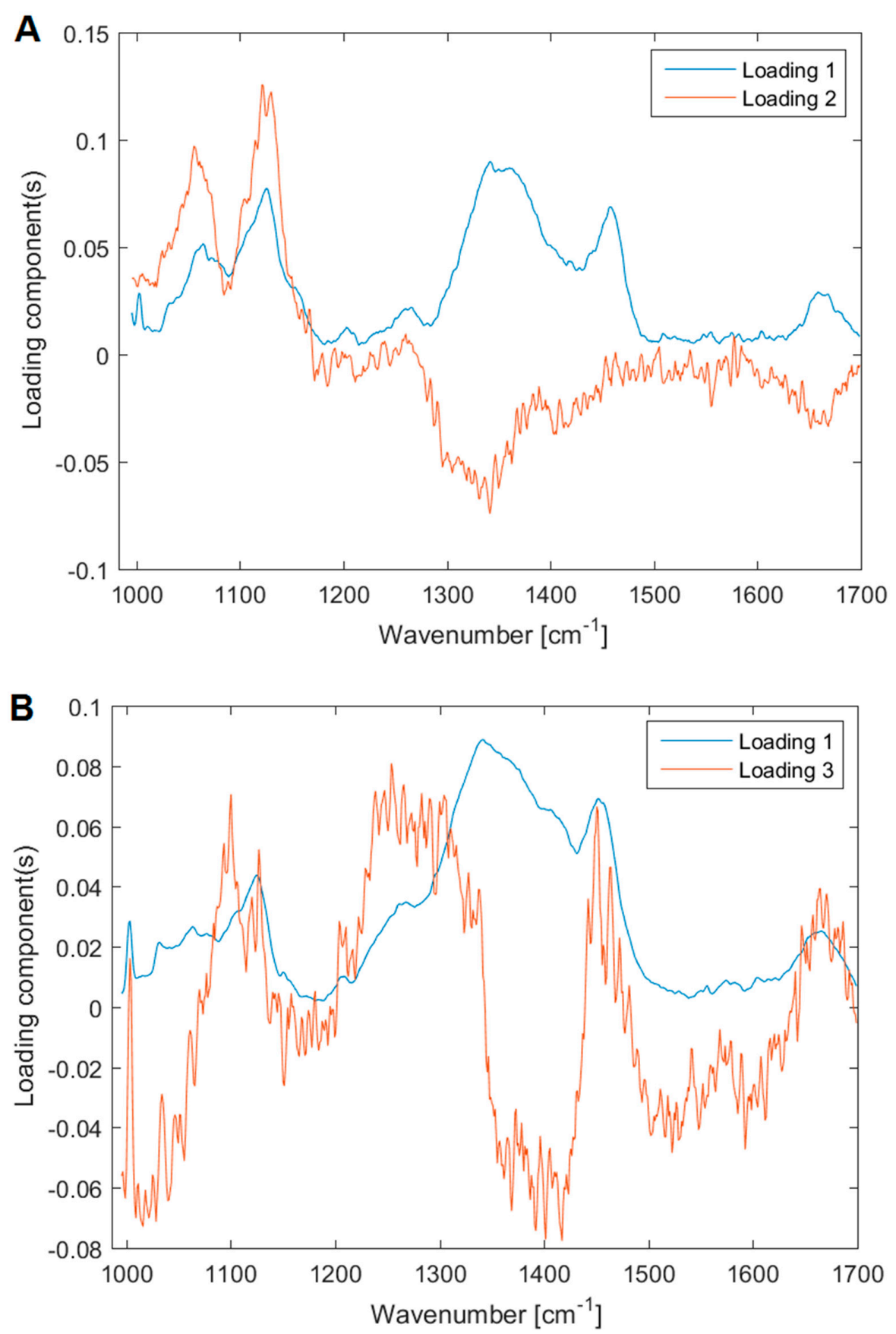

Figure 7. PCA loadings for the two species (A) Candida parapsilosis and (B) Staphylococcus epidermidis. The main differences between the cells that did not yet formed the biofilm and the ones that already produce it are presented mainly in the quantity of the generated proteins, sugars and lipids. 


\section{Conclusions}

In order to study the microbial biofilm structure of Candida parapsilosis and Staphylococcus epidermidis we have investigated different sample preparation techniques for SEM. The effect of sample preparation for conventional SEM allowing surface imaging at room temperature was compared with cryo-SEM techniques employing plunging into various liquid cryogens and HPF. For the cryo-SEM imaging of the biofilm inner structure we have selected the freeze-fracturing technique. We made a comparison of applied techniques for microbial biofilm studies which indeed showed different influences on the final structure of the biofilm. Based on our findings the best candidate for biofilm evaluation can be selected.

We showed that a combination of Raman spectroscopy with selected SEM techniques can provide a deeper insight into the chemistry and composition of biofilms. Such studies involving the influence of variations in the amount of extracellular material during the different stages of biofilm growth are currently under way in our laboratories, making use of a combination of SEM and Raman spectroscopy. We believe that the detailed view of the biofilm structure and composition can advance the better understanding of biofilm structures.

Author Contributions: Conceptualization, K.H., V.K., J.N., F.R. and O.S.; Methodology, K.H., V.K., J.N., and O.S.; Validation, K.H., J.N. and O.S.; Investigation, K.H., V.K., and O.S.; Resources, F.R.; Data Curation, K.H., V.K. and O.S.; Writing-Original Draft Preparation, K.H., V.K., O.S., and Z.P.; Supervision, V.K. and O.S.; Project Administration, V.K.; Funding Acquisition, V.K.

Funding: The research was supported by the Czech Science Foundation (project 17-15451S), the Ministry of Health of the Czech Republic (projects 16-29916A and 16-31593A) and the Ministry of Education, Youth and Sports of the Czech Republic (project LO1212). The research infrastructure was funded by Ministry of Education, Youth and Sports of the Czech Republic and European Commission (projects CZ.1.05/2.1.00/01.0017 and LM2015062 Czech-BioImaging) and by the Czech Academy of Sciences (project RVO:68081731).

Acknowledgments: K.H. is grateful to a FEI/CSMS scholarship for support. K.H. and V.K. thank Roger Wepf for helpful discussions regarding cryo-SEM.

Conflicts of Interest: The authors declare no conflict of interest.

\section{References}

1. Donlan, R.M.; Costerton, J.W. Biofilms: Survival mechanisms of clinically relevant microorganisms. Clin. Microbiol. Rev. 2002, 15, 167-193. [CrossRef] [PubMed]

2. Costerton, J.W.; Stewart, P.S.; Greenberg, E.P. Bacterial biofilms: A common cause of persistent infections. Science 1999, 284, 1318-1322. [CrossRef] [PubMed]

3. Alhede, M.; Qvortrup, K.; Liebrechts, R.; Hoiby, N.; Givskov, M.; Bjarnsholt, T. Combination of microscopic techniques reveals a comprehensive visual impression of biofilm structure and composition. FEMS Immunol. Med. Microbiol. 2012, 65, 335-342. [CrossRef] [PubMed]

4. Ruzicka, F.; Horka, M.; Hola, V. Extracellular Polysaccharides in Microbial Biofilm and Their Influence on the Electrophoretic Properties of Microbial Cells. In Capillary Electrophoresis of Carbohydrates; Volpi, N., Ed.; Humana Press: New York, NY, USA, 2011; pp. 105-126.

5. Donelli, G. Microbial Biofilms: Methods and Protocols; Humana Press: New York, NY, USA, 2014.

6. Flemming, H.C.; Meier, M.; Schild, T. Mini-review: Microbial problems in paper production. Biofouling 2013, 29, 683-696. [CrossRef] [PubMed]

7. Qin, Z.; Ou, Y.; Yang, L.; Zhu, Y.; Tolker-Nielsen, T.; Molin, S.; Qu, D. Role of autolysin-mediated DNA release in biofilm formation of Staphylococcus epidermidis. Microbiology 2007, 153, 2083-2092. [CrossRef] [PubMed]

8. Hola, V.; Ruzicka, F.; Tejkalova, R.; Votava, M. Biofilm formation in nosocomial pathogens of respiratory tract. Int. J. Antimicrob. Agents 2007, 29, S142. [CrossRef]

9. Wimpenny, J. Microbial Metropolis. Adv. Microb. Physiol. 2009, 56, 29-84. [PubMed]

10. Marsh, P.D. Plaque as a biofilm: Pharmacological principles of drug delivery and action in the sub- and supragingival environment. Oral Dis. 2003, 9, 16-22. [CrossRef] [PubMed] 
11. Francolini, I.; Donelli, G. Prevention and control of biofilm-based medical-device-related infections. FEMS Immunol. Med. Microbiol. 2010, 59, 227-238. [CrossRef] [PubMed]

12. Barghi, A.; Sadati, R.; Larki, R.A. Biological Wastewater Treatment through Biofilm. Iran. J. Public Health 2016, 45, 101.

13. Voběrková, S.; Hermanová, S.; Hrubanová, K.; Krzyžánek, V. Biofilm formation and extracellular polymeric substances (EPS) production by Bacillus subtilis depending on nutritional conditions in the presence of polyester film. Folia Microbiol. 2015. [CrossRef] [PubMed]

14. Cresson, R.; Dabert, P.; Bernet, N. Microbiology and performance of a methanogenic biofilm reactor during the start-up period. J. Appl. Microbiol. 2009, 106, 863-876. [CrossRef] [PubMed]

15. Bao, J.; Liu, N.; Zhu, L.; Xu, Q.; Huang, H.; Jiang, L. Programming a Biofilm-Mediated MultienzymeAssembly-Cascade System for the Biocatalytic Production of Glucosamine from Chitin. J. Agric. Food Chem. 2018, 66, 8061-8068. [CrossRef] [PubMed]

16. De la Fuente-Nunez, C.; Cardoso, M.H.; de Souza Candido, E.; Franco, O.L.; Hancock, R.E. Synthetic antibiofilm peptides. Biochim. Biophys. Acta 2016, 1858, 1061-1069. [CrossRef] [PubMed]

17. Huq, A.; Whitehouse, C.A.; Grim, C.J.; Alam, M.; Colwell, R.R. Biofilms in water, its role and impact in human disease transmission. Curr. Opin. Biotechnol. 2008, 19, 244-247. [CrossRef] [PubMed]

18. Sutherland, I.W. Biofilm exopolysaccharides: A strong and sticky framework. Microbiology 2001, 147, 3-9. [CrossRef] [PubMed]

19. Branda, S.S.; Vik, A.; Friedman, L.; Kolter, R. Biofilms: The matrix revisited. Trends Microbiol. 2005, 13, $20-26$. [CrossRef] [PubMed]

20. Sutherland, I.W. The biofilm matrix-An immobilized but dynamic microbial environment. Trends Microbiol. 2001, 9, 222-227. [CrossRef]

21. Adam, B.; Baillie, G.S.; Douglas, L.J. Mixed species biofilms of Candida albicans and Staphylococcus epidermidis. J. Med. Microbiol. 2002, 51, 344-349. [CrossRef] [PubMed]

22. Holá, V.; Růžička, F.; Votava, M. The dynamics of Staphylococcus epidermis biofilm formation in relation to nutrition, temperature, and time. Scr. Med. Fac. Med.Univ. Brun. Masaryk. 2006, 79, 169-174.

23. Liu, H.Y.; Zhao, Y.F.; Zhao, D.; Gong, T.; Wu, Y.C.; Han, H.Y.; Xu, T.; Peschel, A.; Han, S.Q.; Qu, D. Antibacterial and anti-biofilm activities of thiazolidione derivatives against clinical staphylococcus strains. Emerg. Microbes Infect. 2015, 4, e1. [CrossRef] [PubMed]

24. Ruzicka, F.; Horka, M.; Hola, V.; Kubesova, A.; Pavlik, T.; Votava, M. The differences in the isoelectric points of biofilm-positive and biofilm-negative Candida parapsilosis strains. J. Microbiol. Methods 2010, 80, $299-301$. [CrossRef] [PubMed]

25. Deleo, F.; Otto, M.W. Bacterial Pathogenesis: Methods and Protocols; Humana Press: Totowa, NJ, USA, 2008.

26. Paiva, L.C.F.; Vidigal, P.G.; Donatti, L.; Svidzinski, T.I.E.; Consolaro, M.E.L. Assessment of in vitro biofilm formation by Candida species isolates from vulvovaginal candidiasis and ultrastructural characteristics. Micron 2012, 43, 497-502. [CrossRef] [PubMed]

27. Bandara, H.M.H.N.; Lam, O.L.T.; Watt, R.M.; Jin, L.J.; Samaranayake, L.P. Bacterial lipopolysaccharides variably modulate in vitro biofilm formation of Candida species. J. Med. Microbiol. 2010, 59, 1225-1234. [CrossRef] [PubMed]

28. Lattif, A.A.; Mukherjee, P.K.; Chandra, J.; Swindell, K.; Lockhart, S.R.; Diekema, D.J.; Pfaller, M.A.; Ghannoum, M.A. Characterization of biofilms formed by Candida parapsilosis, C. metapsilosis, and C. orthopsilosis. Int. J. Med. Microbiol. 2010, 300, 265-270. [CrossRef] [PubMed]

29. Dohnalkova, A.C.; Marshall, M.J.; Arey, B.W.; Williams, K.H.; Buck, E.C.; Fredrickson, J.K. Imaging hydrated microbial extracellular polymers: Comparative analysis by electron microscopy. Appl. Environ. Microb. 2011, 77, 1254-1262. [CrossRef] [PubMed]

30. Schaudinn, C.; Stoodley, P.; Hall-Stoodley, L.; Gorur, A.; Remis, J.; Wu, S.; Auer, M.; Hertwig, S.; Guerrero-Given, D.; Hu, F.Z.; et al. Death and Transfiguration in Static Staphylococcus epidermidis Cultures. PLoS ONE 2014, 9, e100002. [CrossRef] [PubMed]

31. Lawrence, J.R.; Swerhone, G.D.W.; Leppard, G.G.; Araki, T.; Zhang, X.; West, M.M.; Hitchcock, A.P. Scanning transmission X-ray, laser scanning, and transmission electron microscopy mapping of the exopolymeric matrix of microbial biofilms. Appl. Environ. Microb. 2003, 69, 5543-5554. [CrossRef] 
32. Karcz, J.; Bernas, T.; Nowak, A.; Talik, E.; Woznica, A. Application of lyophilization to prepare the nitrifying bacterial biofilm for imaging with scanning electron microscopy. Scanning 2012, 34, 26-36. [CrossRef] [PubMed]

33. Krzyzanek, V.; Sporenberg, N.; Keller, U.; Guddorf, J.; Reichelt, R.; Schonhoff, M. Polyelectrolyte multilayer capsules: Nanostructure and visualisation of nanopores in the wall. Soft Matter 2011, 7, 7034-7041. [CrossRef]

34. Hrubanova, K.; Nebesarova, J.; Ruzicka, F.; Krzyzanek, V. The innovation of cryo-SEM freeze-fracturing methodology demonstrated on high pressure frozen biofilm. Micron 2018, 110, 28-35. [CrossRef] [PubMed]

35. Biel, S.S.; Wilke, K.; Dunckelmann, K.; Wittern, K.P.; Wepf, R. Light and electron microscopy: Histochemistry on the identical biopsy after high-pressure freezing. J. Histochem. Cytochem. 2004, 52, S62.

36. Hawser, S.P.; Douglas, L.J. Biofilm Formation by Candida Species on the Surface of Catheter Materials in-Vitro. Infect. Immunity 1994, 62, 915-921.

37. Kuo, J. Electron Microscopy: Methods and Protocols; Springer Science \& Business Media: Berlin, Germany, 2007; Volume 369.

38. Montesinos, E.; Esteve, I.; Guerrero, R. Comparison between Direct Methods for Determination of Microbial Cell-Volume-Electron-Microscopy and Electronic Particle Sizing. Appl. Environ. Microb. 1983, 45, 1651-1658.

39. Webster, P.; Wu, S.; Webster, S.; Rich, K.; McDonald, K. Ultrastructural preservation of biofilms formed by non-typeable Hemophilus influenzae. Method Enzymol. 2004, 1, 165-182. [CrossRef]

40. Graham, L.L.; Beveridge, T.J. Effect of Chemical Fixatives on Accurate Preservation of Escherichia-Coli and Bacillus-Subtilis Structure in Cells Prepared by Freeze-Substitution. J. Bacteriol. 1990, 172, 2150-2159. [CrossRef] [PubMed]

41. Hayat, M.A. Principles and Techniques of Scanning Electron Microscopy. Biological Applications, Volume 1; Van Nostrand Reinhold Company: New York, NY, USA, 1974.

42. Wu, Y.; Liang, J.; Rensing, K.; Chou, T.M.; Libera, M. Extracellular Matrix Reorganization during Cryo Preparation for Scanning Electron Microscope Imaging of Staphylococcus aureus Biofilms. Microsc. Microanal. 2014, 20, 1348-1355. [CrossRef] [PubMed]

43. Fassel, T.A.; Edmiston, C.E. Ruthenium red and the bacterial glycocalyx. Biotech. Histochem. 1999, 74, $194-212$. [CrossRef] [PubMed]

44. Reese, S.; Guggenheim, B. A novel TEM contrasting technique for extracellular polysaccharides in in vitro biofilrns. Microsc. Res. Tech. 2007, 70, 816-822. [CrossRef] [PubMed]

45. Galway, M.E.; Heckman, J.W., Jr.; Hyde, G.J.; Fowke, L.C. Advances in High-Pressure and Plunge-Freeze Fixation. Methods Cell Biol. 1995, 49, 3-19. [PubMed]

46. Wang, A.B.; Lin, C.H.; Chen, C.C. The critical temperature of dry impact for tiny droplet impinging on a heated surface. Phys. Fluids 2000, 12, 1622-1625. [CrossRef]

47. Dahl, R.; Staehelin, L.A. High-pressure freezing for the preservation of biological structure: Theory and practice. J. Electron Microsc. Tech. 1989, 13, 165-174. [CrossRef] [PubMed]

48. Moor, H. Theory and Practice of High Pressure Freezing. In Cryotechniques in Biological Electron Microscopy; Steinbrecht, R., Zierold, K., Eds.; Springer: Berlin/Heidelberg, Germany, 1987; pp. 175-191.

49. Studer, D.; Michel, M.; Muller, M. High-Pressure Freezing Comes of Age. Scanning Microsc. 1989, $253-269$.

50. Shimoni, E.; Muller, M. On optimizing high-pressure freezing: From heat transfer theory to a new microbiopsy device. J. Microsc. 1998, 192, 236-247. [CrossRef] [PubMed]

51. Samek, O.; Mlynarikova, K.; Bernatova, S.; Jezek, J.; Krzyzanek, V.; Siler, M.; Zemanek, P.; Ruzicka, F.; Hola, V.; Mahelova, M. Candida parapsilosis Biofilm Identification by Raman Spectroscopy. Int. J. Mol. Sci. 2014, 15, 23924-23935. [CrossRef] [PubMed]

52. Rebrosova, K.; Siler, M.; Samek, O.; Ruzicka, F.; Bernatova, S.; Jezek, J.; Zemanek, P.; Hola, V. Differentiation between Staphylococcus aureus and Staphylococcus epidermidis strains using Raman spectroscopy. Future Microbiol. 2017, 12, 881-890. [CrossRef] [PubMed]

53. Notingher, I.; Hench, L.L. Raman microspectroscopy: A noninvasive tool for studies of individual living cells in vitro. Expert Rev. Med. Devices 2006, 3, 215-234. [CrossRef] [PubMed]

54. Mc, F.J. The nephelometer: An instrument for estimating the number of bacteria in suspensions used for calculating the opsonic index and for vaccines. J. Am. Med. Assoc. 1907, 49, 1176-1178. 
55. Maquelin, K.; Kirschner, C.; Choo-Smith, L.P.; Ngo-Thi, N.A.; van Vreeswijk, T.; Stammler, M.; Endtz, H.P.; Bruining, H.A.; Naumann, D.; Puppels, G.J. Prospective study of the performance of vibrational spectroscopies for rapid identification of bacterial and fungal pathogens recovered from blood cultures. J. Clin. Microbiol. 2003, 41, 324-329. [CrossRef] [PubMed]

56. De Gelder, J.; De Gussem, K.; Vandenabeele, P.; Vancanneyt, M.; De Vos, P.; Moens, L. Methods for extracting biochemical information from bacterial Raman spectra: Focus on a group of structurally similar biomolecules-Fatty acids. Anal. Chim. Acta 2007, 603, 167-175. [CrossRef] [PubMed]

57. Tuma, R. Raman spectroscopy of proteins: From peptides to large assemblies. J. Raman Spectrosc. 2005, 36, 307-319. [CrossRef]

58. Notingher, I. Raman Spectroscopy cell-based Biosensors. Sensors 2007, 7, 1343-1358. [CrossRef]

59. Neugebauer, U.; Schmid, U.; Baumann, K.; Ziebuhr, W.; Kozitskaya, S.; Holzgrabe, U.; Schmitt, M.; Popp, J. The influence of fluoroquinolone drugs on the bacterial growth of S-epidermidis utilizing the unique potential of vibrational spectroscopy. J. Phys. Chem. A 2007, 111, 2898-2906. [CrossRef] [PubMed]

60. De Gelder, J.; De Gussem, K.; Vandenabeele, P.; Moens, L. Reference database of Raman spectra of biological molecules. J. Raman Spectrosc. 2007, 38, 1133-1147. [CrossRef]

61. Perna, G.; Lastella, M.; Lasalvia, M.; Mezzenga, E.; Capozzi, V. Raman spectroscopy and atomic force microscopy study of cellular damage in human keratinocytes treated with $\mathrm{HgCl}_{2}$. J. Mol. Struct. 2007, 834, 182-187. [CrossRef]

62. Pyrgiotakis, G.; Bhowmick, T.K.; Finton, K.; Suresh, A.K.; Kane, S.G.; Bellare, J.R.; Moudgil, B.M. Cell (A549)-particle (Jasada Bhasma) interactions using Raman spectroscopy. Biopolymers 2008, 89, 555-564. [CrossRef] [PubMed]

63. Pilat, Z.; Bernatova, S.; Jezek, J.; Kirchhoff, J.; Tannert, A.; Neugebauer, U.; Samek, O.; Zemanek, P. Microfluidic Cultivation and Laser Tweezers Raman Spectroscopy of E. coli under Antibiotic Stress. Sensors 2018, 18, 1623. [CrossRef] [PubMed]

64. Rebrosova, K.; Siler, M.; Samek, O.; Ruzicka, F.; Bernatova, S.; Hola, V.; Jezek, J.; Zemanek, P.; Sokolova, J.; Petras, P. Rapid identification of staphylococci by Raman spectroscopy. Sci. Rep. 2017, 7, 14846. [CrossRef] [PubMed]

65. Samek, O.; Obruca, S.; Siler, M.; Sedlacek, P.; Benesova, P.; Kucera, D.; Marova, I.; Jezek, J.; Bernatova, S.; Zemanek, P. Quantitative Raman Spectroscopy Analysis of Polyhydroxyalkanoates Produced by Cupriavidus necator H16. Sensors 2016, 16, 1808. [CrossRef] [PubMed]

66. Ruzicka, F.; Hola, V.; Votava, M.; Tejkalova, R. Importance of biofilm in Candida parapsilosis and evaluation of its susceptibility to antifungal agents by colorimetric method. Folia Microbiol. 2007, 52, 209-214. [CrossRef]

67. Azeredo, J.; Azevedo, N.F.; Briandet, R.; Cerca, N.; Coenye, T.; Costa, A.R.; Desvaux, M.; Di Bonaventura, G.; Hebraud, M.; Jaglic, Z.; et al. Critical review on biofilm methods. Crit. Rev. Microbiol. 2017, 43, 313-351. [CrossRef] [PubMed]

68. Haque, F.; Alfatah, M.; Ganesan, K.; Bhattacharyya, M.S. Inhibitory Effect of Sophorolipid on Candida albicans Biofilm Formation and Hyphal Growth. Sci. Rep. 2016, 6, 23575. [CrossRef] [PubMed]

69. Ludecke, C.; Jandt, K.D.; Siegismund, D.; Kujau, M.J.; Zang, E.; Rettenmayr, M.; Bossert, J.; Roth, M. Reproducible Biofilm Cultivation of Chemostat-Grown Escherichia coli and Investigation of Bacterial Adhesion on Biomaterials Using a Non-Constant-Depth Film Fermenter. PLoS ONE 2014, 9, e84837. [CrossRef] [PubMed]

70. Bray, D.F.; Bagu, J.; Koegler, P. Comparison of Hexamethyldisilazane (Hmds), Peldri-Ii, and Critical-Point Drying Methods for Scanning Electron-Microscopy of Biological Specimens. Microsc. Res. Tech. 1993, 26, 489-495. [CrossRef] [PubMed]

71. Hazrin-Chong, N.H.; Manefield, M. An alternative SEM drying method using hexamethyldisilazane (HMDS) for microbial cell attachment studies on sub-bituminous coal. J. Microbiol. Methods 2012, 90, 96-99. [CrossRef] [PubMed]

72. Osumi, M.; Konomi, M.; Sugawara, T.; Takagi, T.; Baba, M. High-pressure freezing is a powerful tool for visualization of Schizosaccharomyces pombe cells: Ultra-low temperature and low-voltage scanning electron microscopy and immunoelectron microscopy. J. Electron Microsc. 2006, 55, 75-88. [CrossRef] [PubMed]

73. Psenicka, M.; Tesarova, M.; Tesitel, J.; Nebesarova, J. Size determination of Acipenser ruthenus spermatozoa in different types of electron microscopy. Micron 2010, 41, 455-460. [CrossRef] [PubMed] 
74. Brandt, N.N.; Brovko, O.O.; Chikishev, A.Y.; Paraschuk, O.D. Optimization of the rolling-circle filter for Raman background subtraction. Appl. Spectrosc. 2006, 60, 288-293. [CrossRef] [PubMed]

75. Wold, S.; Esbensen, K.; Geladi, P. Principal Component Analysis. Chemom. Intell. Lab. 1987, 2, 37-52. [CrossRef]

76. Kaech, A.; Ziegler, U. High-Pressure Freezing: Current State and Future Prospects. Methods Mol. Biol. 2014, 1117, 151-171. [PubMed]

77. Kaech, A.; Woelfel, M. Evaluation of Different Freezing Methods for Monolayer Cell Cultures. Microsc. Microanal. 2007, 13, 240-241. [CrossRef]

78. Donlan, R.M. Biofilms: Microbial life on surfaces. Emerg. Infect. Dis. 2002, 8, 881-890. [CrossRef] [PubMed]

79. Mahapatra, S.; Banerjee, D. Fungal exopolysaccharide: Production, composition and applications. Microbiol. Insights 2013, 6, 1-16. [CrossRef] [PubMed]

80. Maira-Litran, T.; Kropec, A.; Abeygunawardana, C.; Joyce, J.; Mark, G.; Goldmann, D.A.; Pier, G.B. Immunochemical properties of the staphylococcal poly- $N$-acetylglucosamine surface polysaccharide. Infect. Immunity 2002, 70, 4433-4440. [CrossRef]

(C) 2018 by the authors. Licensee MDPI, Basel, Switzerland. This article is an open access article distributed under the terms and conditions of the Creative Commons Attribution (CC BY) license (http:/ / creativecommons.org/licenses/by/4.0/). 